\title{
Synergy between Printex nano-carbons and silver nanoparticles for sensitive estimation of antioxidant activity
}

\author{
Paulo A. Raymundo-Pereira ${ }^{\text {a, }}$, Anderson M. Campos ${ }^{a}$, Thiago M. Prado a, \\ Leonardo N. Furini ${ }^{b}$, Naiza V. Boas ${ }^{a}$, Marcelo L. Calegaro ${ }^{\text {a }}$, Sergio A.S. Machado ${ }^{\text {a }}$ \\ a Instituto de Química de São Carlos, Universidade de São Paulo, São Carlos, São Paulo, CEP 13566-590, Brazil \\ ${ }^{\mathrm{b}}$ Faculdade de Ciências e Tecnologia, UNESP Univ Estadual Paulista, 19060-900 Presidente Prudente, São Paulo, Brazil
}

\section{H I G H L I G H T S}

- We highlight the use of Printex L6 nano-carbon as a much cheaper alternative to carbon nanotubes and graphene.

- The hybrid nanomaterial was completely characterized by MET, EDX, SAED, DRX, RAMAN and cyclic voltammetry.

- The silver nanoparticles (size range 1-2 $\mathrm{nm}$ ) were prepared directly onto the surface of the Printex 6L Carbon "nanocarbon".

- An ultrathin film PC-AgNP nanostructured showed a synergetic effect between PC nanocarbons and AgNP. - Sensitive estimation of antioxidants at a low applied potential (91 mV vs. $\mathrm{Ag} / \mathrm{AgCl})$ and low detection limit $\left(63.3 \mathrm{nmol} \mathrm{L}^{-1}\right)$.

\section{A R T I C L E I N F O}

\section{Article history:}

Received 22 February 2016

Received in revised form

20 April 2016

Accepted 21 April 2016

Available online 27 April 2016

\section{Keywords:}

Hybrid material

Silver nanoparticles

Printex L6 carbon

Sensing

Polyphenols estimation

Wine
G R A P H I C A L A B S T R A C T

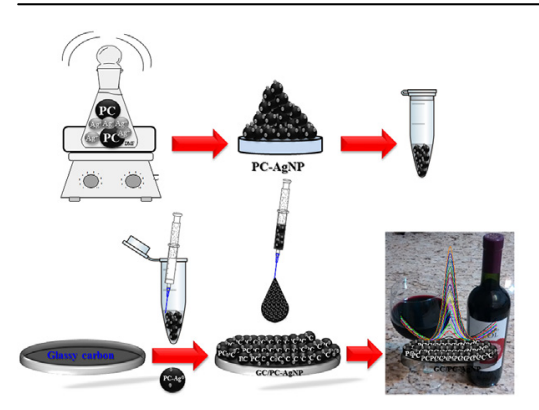

* Corresponding author. São Carlos Institute of Chemistry, University of São Paulo, CP 380, CEP 13566-590, São Carlos, São Paulo, Brazil.

E-mail address: pauloaugustoraymundopereira@gmail.com (P.A. RaymundoPereira). 
fabricating the reproducible GC/PC-Ag electrodes is entirely generic and may be explored for other types of (bio)sensors and devices.

\section{Introduction}

The development of analytical methodologies for the detection and quantification of polyphenolic compounds, especially those naturally present in foods, has become a subject of great interest because such organic molecules have biological properties associated with human health, including antiinflammatory, antihistaminic, and antitumor activities, together with the ability to scavenge free radicals [1]. These antioxidant polyphenolic compounds are able to alleviate several diseases associated with oxidative stress, including cardiovascular and neurodegenerative disorders [1,2]. Gallic acid (GA), or 3,4,5-tri-hydroxybenzoic acid, is a major source of dietary antioxidants and is one of the main phenolic compounds found in grapes, black tea, several plants and humic substances [1]. The presence of one or several phenolic groups is responsible for the antioxidant activity of GA, which is capable of reducing the toxic effects of reactive oxygen species and radical compounds [2].

The development of sensitive and robust methods for GA determination is important due to the positive effects of phenolic antioxidants on human health [1]. The "determination of total phenols" is complicated because of their chemical complexity and difficulties in the extraction process, as well as in dealing with food sample matrices [1]. A good indication of the level of antioxidants present in any sample [3] can be obtained in an indirect manner by the estimation of "total polyphenols" using spectrophotometric protocols (Folin-Ciocalteu method) based on the reaction of phenolics with a colorimetric reactant, thereby allowing their measurement in the visible region of the spectrum [4].

The analytical performance for GA determination, including sensitivity and selectivity, can be obtained using methodologies such as liquid and gas chromatography; however, these analyses cannot be easily performed on a routine basis due to constraints and cost [2]. Alternatively, electrochemical sensors can be a suitable alternative for rapid, reliable and cost-effective in-situ analysis. A wide variety of electrode materials, including nanostructured materials, can be used to improve the sensitivity, selectivity, stability of GA detection [5-7] and allow for the possibility of discrimination between different compounds or polyphenol classes [2]. Among them, carbon nanotubes (CNT) and graphene (GO) have paved the way for new and improved sensing devices, owing to their good mechanical, chemical and electrical properties, [6-9]. In contrast, the bright prospects for the use of CNT, GO and fullerenes are overshadowed by their prohibitively high production costs and issues with purity [10].

As an alternative to the nanostructured carbon materials previously mentioned, the Arduini and Compton groups $[2,11,12]$ have demonstrated the successful use of carbon black (CB) for several electrochemical sensors. In order to identify carbon materials with improved electroanalytical performance, the Compton group reported the advantageous use of carbon black as a much cheaper alternative to carbon nanotubes as a sensor for nicotine determination [12]. In this regard, Santos and co-workers [15] recently reported a comparative study between carbon black and Printex L6 carbon (PC) for the electrogeneration of hydrogen peroxide, with the better results being obtained for PC. In the same study, the authors summarized the main properties of the PC. As they related, $\mathrm{PC}$ is a commercial carbon material and can be defined as an alkaline pigment of furnace type with excellent physical, chemical and electrochemical properties [15]. It presents the BrunauerEmmett-Teller (BET) surface of $265 \mathrm{~m}^{2} \mathrm{~g}^{-1}$, a density of $1.8 \mathrm{~g} \mathrm{~cm}^{-3}$ and primary use in organic degradation, where PC was used for the degradation of phenols [16] and hexane [17], for catechol oxidation and for removing organic pollutants from secondary effluents $[18,19]$. PC has been extensively investigated by the Lanza group for the electrochemical generation of hydrogen peroxide in alkaline aqueous solution, oxygen reduction to hydrogen peroxide, electro-fenton degradation of the food dye amaranth and electrogeneration of hydrogen peroxide in acid medium using PCs with $\mathrm{Fe}_{3} \mathrm{O}_{4}$ nanoparticles, cobalt(II) and manganese(II) phthalocyanines [20-24]. The main differences between PC and other carbonaceous materials (carbon nanotubes and graphene) include: i) a better heterogeneous electron transfer constant in the presence of a ferricyanide redox mediator; ii) an improvement in terms of reduced overpotential and/or low background current for several analytes; iii) more uniform coverage of the working electrode than CNT and GO, which display cluster structures, influencing direct under sensitivity $[13,14]$.

A wide variety of nanomaterials, especially metal nanostructures with different properties, have found broad application in several analytical methods [25]. Carbonaceous materials decorated with transition metal nanoparticles including gold, nickel, antimony, copper, platinum, bismuth and silver [7,10,26-32] have been used to increase the activity of sensors electrochemicals. In the case of electrochemical sensors, the modification of electrode surfaces using AgNPs has received wide-spread attention mainly due to their interesting electrocatalytic properties $[2,7,9]$. In this work, we report a study focusing on the synthesis, characterization and application of a novel nanocomposite based on AgNPs supported directly on PC. This novel hybrid nanomaterial yielded excellent sensitivity for GA electro-oxidation, as well as a high synergetic effect, good analytical performance and a low detection limit. The sensor developed with the hybrid PC-Ag nanomaterial is shown to be promising for fast, simple and sensitive determination of GA and can be used for the estimation of total polyphenols in wine samples.

\section{Experimental section}

\subsection{Reagents and solutions}

All chemicals were of analytical grade and were used without further purification. Silver nitrate (99\% purity) was obtained from Merck (Darmstadt, Germany). Gallic acid and dimethylformamide (DMF) were obtained from Sigma-Aldrich (St. Louis, MO, USA) and ethylene glycol was obtained from Carlo Erba (France). 4aminoantipyrine (AAP) was purchased from Sigma-Aldrich (St. Louis, MO, USA); potassium hexacyanoferrate(III) $\left(\mathrm{K}_{3}\left[\mathrm{Fe}(\mathrm{CN})_{6}\right]\right)$ was purchased from J. T. Baker (Center Valley, PA, USA); anhydrous sodium tetraborate was purchased from Nuclear (Brazil); boric acid was purchased from Synth (Brazil); sodium hydroxide was purchased from Merck (Brazil). The PC was purchased from Degussa (Essen, North Rhine-Westphalia, Germany). High purity nanopure water (resistance, $18>\mathrm{M} \Omega \mathrm{cm}^{-1}$ ) was obtained from a Nanopure Ultrapurification System (Barnstead Inc., Waltham, MA, USA). The $0.1 \mathrm{~mol} \mathrm{~L}^{-1}$ phosphate buffer solution ( $\mathrm{pH} 7.0$ ) was home prepared 
with sodium phosphate dibasic and sodium phosphate monobasic monohydrate from Sigma-Aldrich (St. Louis, MO, USA) and then employed as a supporting electrolyte. The stock solutions of GA $\left(1.0 \times 10^{-3} \mathrm{~mol} \mathrm{~L}^{-1}\right)$ were freshly prepared by dissolution of an appropriate amount of GA in $25 \mathrm{~mL}$ of phosphate buffer solution. All experiments were performed at room temperature (approximately $\left.25^{\circ} \mathrm{C}\right)$.

\subsection{Synthesis of the silver nanoparticles supported directly on carbon}

The silver nanoparticles were synthesized directly on PC as proposed by Skrabalak et al. [33], based on the polyol method using ethylene glycol (EG) as a reducing agent (see Fig. 1). Specifically, $3.0 \mathrm{~g}$ of PC were suspended in $25 \mathrm{~mL}$ of EG, then $0.71 \mathrm{~mol}$ of $\mathrm{AgNO}_{3}$ was added and the mixture was heated for $1 \mathrm{~h}$ at $150{ }^{\circ} \mathrm{C}$. The temperature of $150{ }^{\circ} \mathrm{C}$ was selected to synthesize the silver nanoparticles supported directly on carbon because at this value EG is oxidized to glycolaldehyde (GA), the reductant agent. In fact, EG is also necessary to control the AgNP size by forming a stable silver complex with the dispersed silver ions, which are subsequently reduced by GA. Silver nitrate is stable at $150{ }^{\circ} \mathrm{C}$, but as mentioned above, there is no free silver nitrate in the reaction media. The TEM images shows that the polyol synthesis has been successful in generating Ag nanostructures with well-defined and controllable shapes. PC is a functionalized materials containing several oxygenated functional groups on the surface, such as $-\mathrm{OH}$ and $-\mathrm{COOH}$. We believe that the AgNP are formed by the interaction of the silver complex with that functional groups which are subsequently reduced at $150^{\circ} \mathrm{C}$ when GA is formed. The solid was filtered and washed with high purity water. The obtained product was dried at $90^{\circ} \mathrm{C}$ for $12 \mathrm{~h}$ and stored in a vacuum at room temperature. The hybrid material was denoted as PC-Ag.

\subsection{Characterization techniques}

The morphological aspects of the PC-Ag were examined using high-angle annular dark-field transmission electron microscopy (HAADF-TEM) with an FEI TECNAI G2 F20 transmission electron microscope operating at $200 \mathrm{kV}$. The powder was ultrasonically suspended in ethanol for $60 \mathrm{~min}$, and the suspension was deposited onto carbon-coated copper grids.

The structural characterization was performed by X-ray powder diffraction (XRD) using a Rigaku Rotaflex diffractometer model RU200B at $50 \mathrm{kV}$ and $100 \mathrm{~mA}$, with a $\mathrm{Cu}_{\mathrm{K} \alpha}$ radiation wavelength of $\lambda=1.542$ Å. The Raman spectra were collected using a microRaman in-Via Renishaw spectrograph (Renishaw Ltd, Gloucestershire, UK) coupled to a Leica optical microscope, under wavelength of excitation at $514.5 \mathrm{~nm}$, diffraction grating of $1800 \mathrm{~L} \mathrm{~mm}^{-1}$, acquisition time of $10 \mathrm{~s}$ and 10 accumulations.

Differential pulse voltammetry (DPV) and cyclic voltammetry (CV) experiments were performed using a model PGSTAT 302 Autolab electrochemical system (Eco Chemie, Utrecht, Netherlands) coupled to a computer and controlled by GPES 4.9.9 software. The electrochemical cell was used with conventional three-electrode system: a GC electrode modified with PC-AgNP as a work electrode, an $\mathrm{Ag} / \mathrm{AgCl}$ electrode in $\mathrm{KCl}\left(3.0 \mathrm{~mol} \mathrm{~L}^{-1}\right)$ as a reference electrode, and platinum wire as an auxiliary electrode. All electrochemical measurements were performed in $0.1 \mathrm{~mol} \mathrm{~L}^{-1}$ phosphate buffer solution ( $\mathrm{pH} 7.0$ ) at a controlled temperature $\left(25^{\circ} \mathrm{C}\right)$. CV experiments were performed in a potential range from -0.2 to $+0.6 \mathrm{~V}$, with a scan rate of $50 \mathrm{mV} \mathrm{s}^{-1}$. DPV experiments were performed using a scan rate at $5 \mathrm{mV} \mathrm{s}^{-1}$, pulse amplitude at $50 \mathrm{mV}$ and modulation time at $1 \mathrm{mV}$. The potential range varied from -0.2 to $+0.6 \mathrm{~V}$ for comparative and optimization studies as well as calibration curves.

Spectrophotometric measurements were performed using an Avaspec 2048 spectrophotometer (Avantes BV) and a quartz cuvette with path length of $0.1 \mathrm{~cm}$.

\subsection{Preparation of the electrode}

Prior to modification, the GC electrode surface was polished with $0.3 \mu \mathrm{m}$ alumina slurries, rinsed thoroughly with nanopure

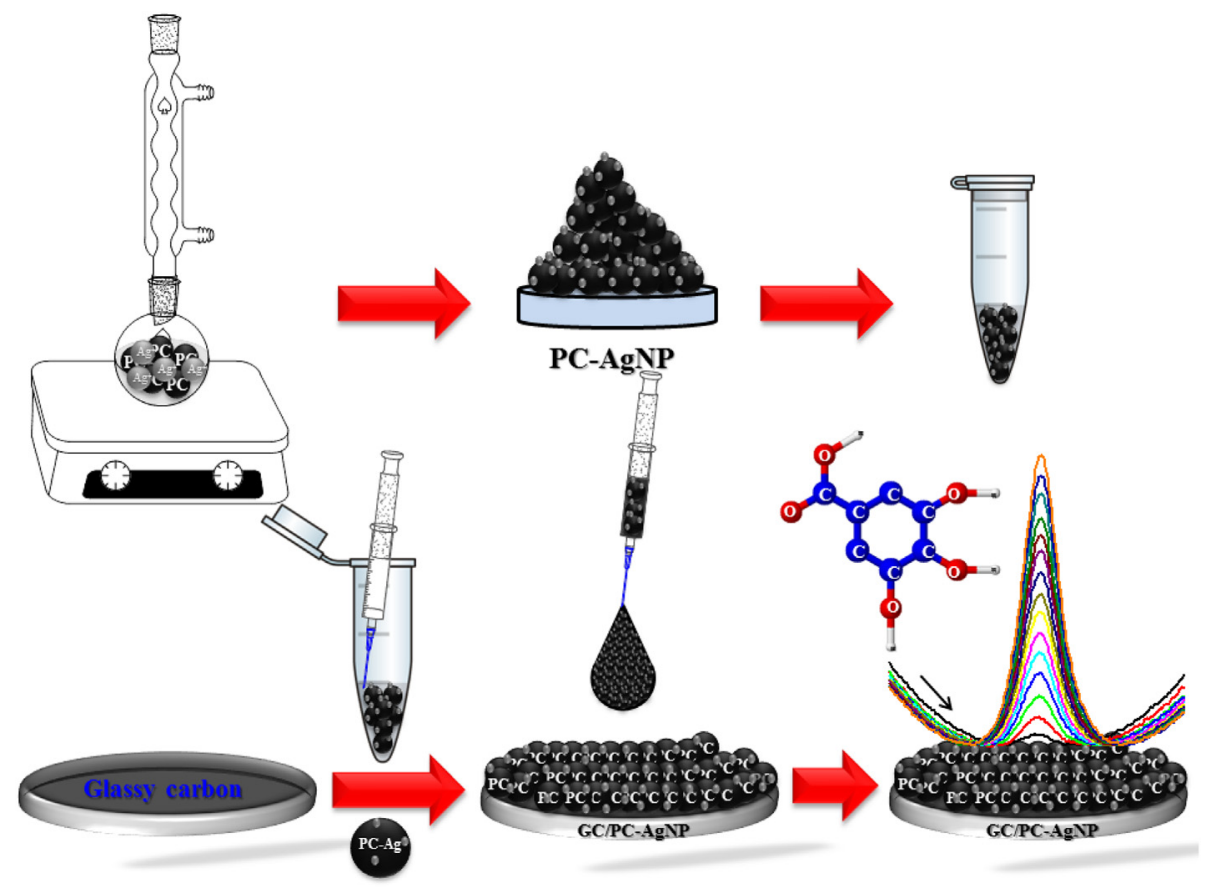

Fig. 1. Schematic display of the different steps involved in the preparation of the sensor for GA. 
water, sonicated for $5 \mathrm{~min}$ in isopropanol and $5 \mathrm{~min}$ in water, and dried in air. $1.0 \mathrm{mg}$ of PC-AgNP was suspended in $1.0 \mathrm{~mL}$ of DMF. The suspension was dispersed using ultrasonic stirring for $2 \mathrm{~h}$. A film coating layer $(6.0 \mathrm{uL})$ was prepared on the GC electrode surface by casting the suspension using a micropipette as shown in Fig. 1. The film was dried for $2 \mathrm{~h}$ at room temperature. DMF was used due to its higher compatibility with the hydrophobic GC surface as compared to others solvents (e.g., ethanol, acetone), yielding a more homogeneous film.

\subsection{Analytical procedure}

The GC, GC/PC and PC-AgNP electrodes were electrochemically characterized by estimating the surface concentration of electroactive species using the silver oxidation peak (charge). The GC, GC/ PC and GC/PC-Ag electrodes were then evaluated to detect GA by DPV. After choosing the best electrode for the ultrasensitive determination of GA, the experimental parameters of the DPV technique (scan rate, pulse amplitude, and modulation time) were optimized.

Analytical curves were then constructed by adding small volumes of concentrated standard solutions of GA into the electrochemical cell containing $20 \mathrm{~mL}$ of $0.1 \mathrm{~mol} \mathrm{~L}^{-1}$ phosphate buffer solution ( $\mathrm{pH}$ 7.0). All measurements were performed in triplicate $(\mathrm{n}=3)$ for each concentration. The detection limit (LOD) was calculated according to the statistical method described by Miller $[34,35]$ and can be defined by LOD $=y_{\mathrm{B}}+3 S_{\mathrm{B}}$ where $y_{\mathrm{B}}$ is the intercept of the calibration plot used as the blank signal and the regression curve standard deviation $S_{y / x}$ was used as $S_{B}$. It is important to note that, using this methodology, it is not necessary to perform several repetitions of the blank measurement since the $S_{\mathrm{B}}$ parameter is obtained directly from the analytical curve. Ni's group reported several voltammetric and spectrophotometric studies of the evaluation of LOD using this simple method [36-38]. The precision of the proposed method was verified from inter-day $(n=5)$ and intra-day $(n=10)$ repeatability studies.

Analyses of GA in the red wine sample by the proposed voltammetric method were carried out using triplicate samples of wines commercially available in Brazil. For comparison reasons, all of the samples examined were produced recently, stored in the dark at $10^{\circ} \mathrm{C}$, and analyzed shortly after being opened. An aliquot of $50 \mu \mathrm{L}$ of red wine was added into the voltammetric cell containing $10 \mathrm{~mL}$ of phosphate buffer ( $\mathrm{pH} \mathrm{7.0)}$ ) and homogenized with a magnetic stirrer. The differential pulse voltammograms were recorded in the potential range from -0.2 to $+0.6 \mathrm{~V}$, using a scan rate of $5 \mathrm{mV} \mathrm{s}^{-1}$, a modulation time of $50 \mathrm{~ms}$, and pulse amplitude of $50 \mathrm{mV}$. The GA content in these samples was determined and compared statistically with the standard method based on spectrophotometric response alternatively to the Folin-Ciocalteu method. The content of total polyphenols in the red wine sample was determined using the 4aminoantipyrine method (4-AAPM) in alkaline medium. The polyphenols were oxidized by $\mathrm{K}_{3}\left[\mathrm{Fe}(\mathrm{CN})_{6}\right]$ and then complexed by 4-AAP causing a color change in the solution, with the wavelength of maximum absorbance ( $\lambda=489 \mathrm{~nm}$ ) being proportional to the content of polyphenols. This is an alternative approach to the Folin-Ciocalteu method, commonly used for food analysis $[39,40]$. The absorbance measurements of the wine after 1:30 dilution in borate buffer solution $(\mathrm{pH} 11)$ were interpolated on a calibration curve created with the following standard solution concentrations of GA: $8.88 \times 10^{-5}, 1.77 \times 10^{-4}$, $2.66 \times 10^{-4}, 3.54 \times 10^{-4}$ and $4.43 \times 10^{-4} \mathrm{~mol} \mathrm{~L}^{-1}$, in borate buffer solution ( $\mathrm{pH} 11)$.

\section{Results and discussion}

\subsection{Morphological and structural performance}

High-angle annular dark-field transmission electron microscopy (HAADF-TEM) was used to obtain information about the structure, morphology and composition of the hybrid PC-AgNP material (Fig. 2A and B). This method is highly sensitive to the atomic number of the atoms present in the sample. In the case of metal nanoparticles supported on carbon, the metallic particles are brighter than the carbon particles. This effect is clear from the images presented in Fig. 2. TEM images confirmed that the AgNPs (size range 1-2 $\mathrm{nm}$ ) were well-distributed throughout the hybrid material and no aggregation was observed. Furthermore, the nanoball shape of the PC was noted, with size ranging between 20 and $25 \mathrm{~nm}$. From Fig. 2A and B, we can also verify that the carbon particles maintained their nanoball shape after decoration with the AgNPs. The EDX spectrum was used to confirm the formation of AgNPs as well as the presence of carbon nanoparticles in the hybrid material (Fig. 2C). The copper and carbon signals were caused by the copper composition of the grids coated with carbon film used for HAADF-TEM analysis. Furthermore, Fig. 2C presented show clearly the presence of $\mathrm{Ag}$ in the sample analyzed. The corresponding electron diffraction (SAED) pattern (inset Fig. 2C) confirmed the formation of amorphous carbon and AgNPs with a single crystalline nature. The distribution of the AgNPs afforded good electrocatalytic properties to the hybrid material, and the resulting material has potential applications as a substrate for the development of electrochemical sensors.

Fig. 3A shows the X-ray diffraction pattern of synthesized crystalline AgNPs on PC. The corresponding powder XRD pattern of PC-AgNP demonstrates the formation of AgNPs. The diffraction pattern shows five sharp and well defined diffraction peaks at $2 \theta=38.48^{\circ}, 44.34^{\circ}, 64.65^{\circ}$ and $77.67^{\circ}$, which can be assigned to the (111), (200), (220) and (311) reflections of the face centered cubic (fcc) structure of metallic silver, respectively. The diffraction pattern corresponds to JCPDS File No. 04-0783 [41] while $2 \theta=25.01^{\circ}$ corresponds to the (002) plane of the hexagonal phase of the carbon support, according to JCPDF 73-2096 [15]. In the study reported by Assumpção et al. [15] the presence of $\mathrm{SO}_{2}$ groups highlighted in the PC diffractogram was confirmed by the ATR-FTIR spectra showing a band at $1078 \mathrm{~cm}^{-1}$ related to $\mathrm{SO}_{2}$ groups. The well-defined intense peaks in the diffraction pattern indicated excellent crystallinity of the AgNPs. The small size of the Ag diffraction peaks indicated the formation of very small Ag particles (nanometer scale), in agreement with the HAADF-TEM images.

Raman spectroscopy analysis in Fig. 3B was carried out, since it can provide important complementary data related to the surface functionalization of the PC and PC-Ag hybrid nanomaterials approach [42,43]. The samples exhibited two prominent graphite-related bands, which corresponded to the well-known D $\left(\sim 1355 \mathrm{~cm}^{-1}\right)$ and $\mathrm{G}\left(\sim 1597 \mathrm{~cm}^{-1}\right)$ bands, assigned to defects and edge effects in $\mathrm{sp}^{2}$ hybridized carbon lattices and to the $\mathrm{C}-\mathrm{C}$ bond stretching, respectively. Displacement of D and $G$ bands between the PC and PC-Ag samples was not observed. In addition, a large band at $\sim 2700 \mathrm{~cm}^{-1}$ was observed and consisted of two less intense bands, namely 2D $\left(\sim 2670 \mathrm{~cm}^{-1}\right)$ and $\mathrm{D}+\mathrm{D}^{\prime}\left(\sim 2832 \mathrm{~cm}^{-1}\right)$ [44]. The 2D band, a D band overtone, is related to the crystallinity of the material $[42,43]$.

The intensity ratio of the $\mathrm{D}$ - and $\mathrm{G}$-bands $\left(\mathrm{I}_{\mathrm{D}} / \mathrm{I}_{\mathrm{G}}\right)$ indicates a surface functionalization progress and could also be related to the relative disorder in the carbonaceous structures $[42,43]$. The $I_{D} / I_{G}$ ratio (integrated areas ratio in agreement with that reported by Ferrari and Robertson [45]) for PC and PC-AgNP was found to be 1.04 and 1.07, respectively, which are consistent with the 

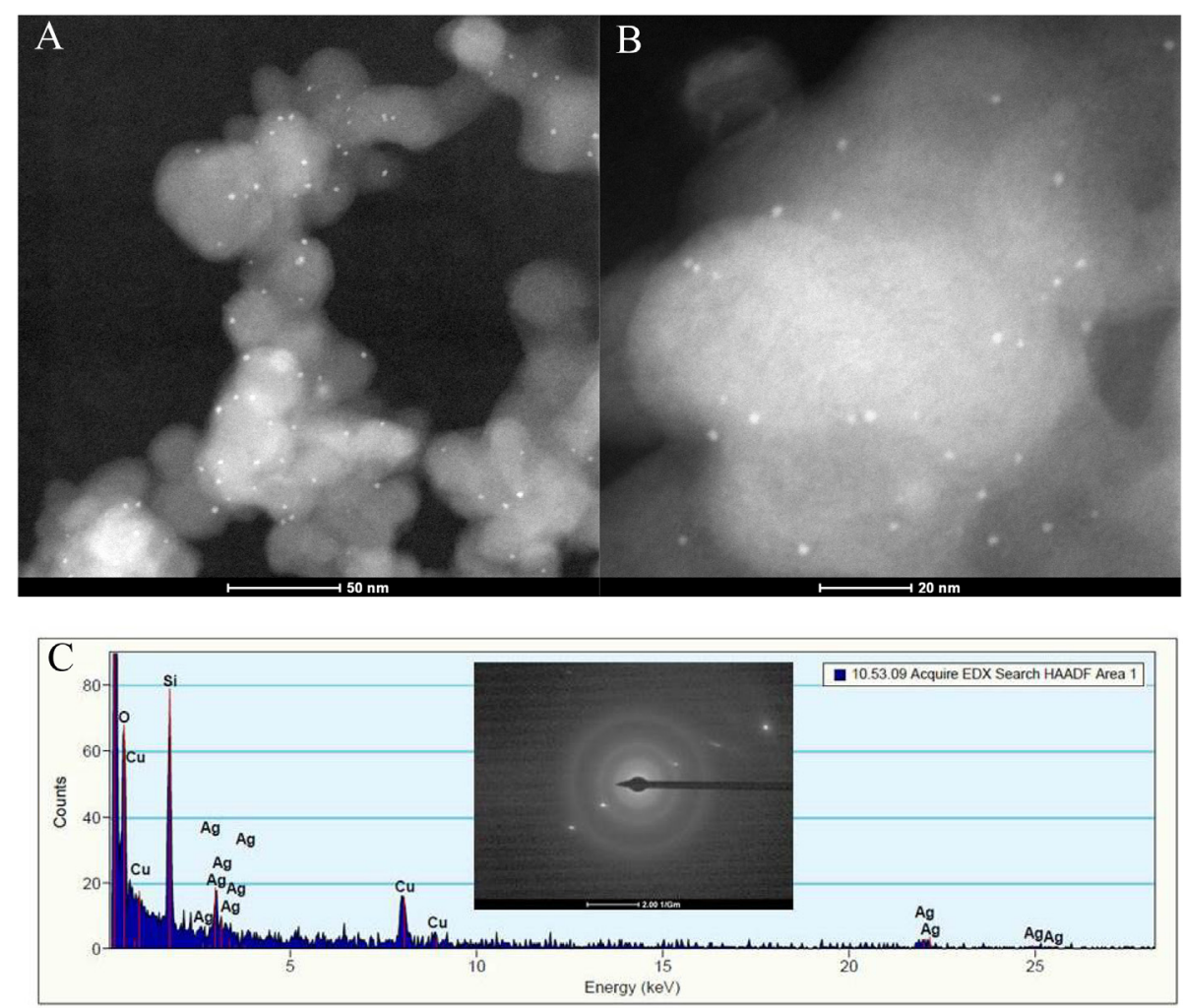

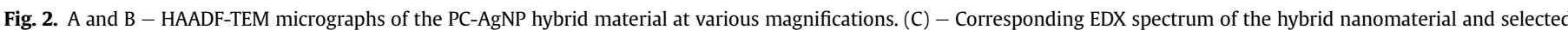
area electron diffraction (SAED) pattern (inset).
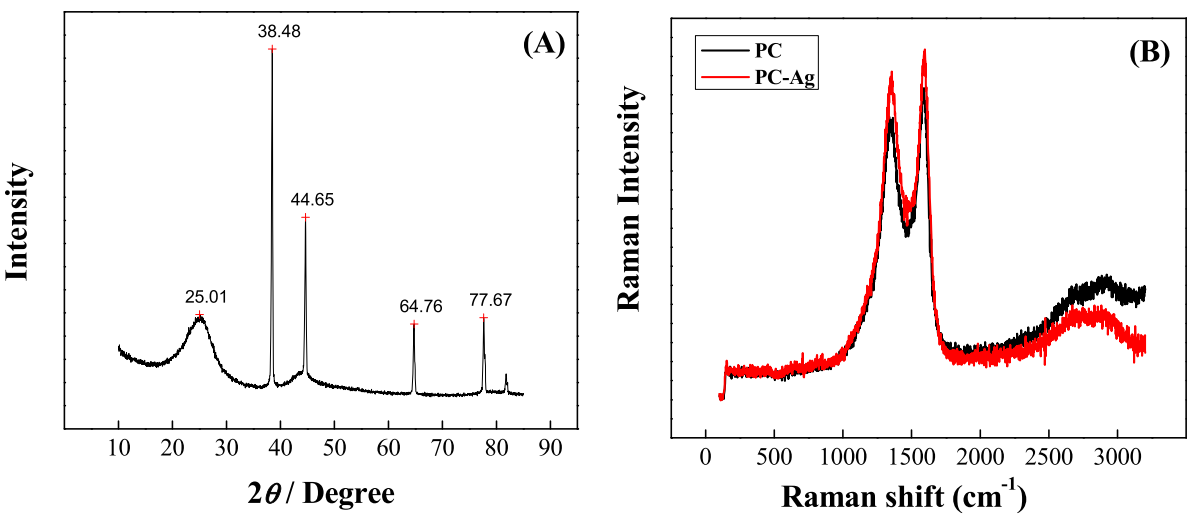

Fig. 3. (A) XRD patterns of PC-AgNP hybrid nanomaterial and (B) Raman spectra of PC and PC-AgNP hybrid nanomaterial

functionalization degree (i.e. surface disorder) [13]. It should be noted that an $\mathrm{I}_{\mathrm{D}} / \mathrm{I}_{\mathrm{G}}$ value $>1$ indicates that $\mathrm{CB}$ is in the transition from graphite to nanocrystalline graphite [45]. In addition, this ratio for was 1.07 for PC-Ag, similar to its precursor (1.04), thus indicating that the composite formation did not seem to induce defects within the ribbon domains and/or structural disorder $[42,43]$; in agreement with XRD data. Moreover, Mehl and coworkers [43] reported that Raman signals of rGO or GO were increased by attached noble metallic NPs, similarly, carbon nanotubes attached to metallic nanostructures has been enhanced [43]. A few less intense bands, namely 2D $\left(\sim 2670 \mathrm{~cm}^{-1}\right)$ and $\mathrm{D}+\mathrm{D}^{\prime}$ $\left(\sim 2832 \mathrm{~cm}^{-1}\right)$, were also observed in Fig. $3 \mathrm{~B}$, and were similar to those previously observed [43]. The 2D band, a D band overtone, is related to the crystallinity of the carbon material $[42,43]$. Thus, the increased intensity of PC bands in the presence of AgNPs may indicate that this hybrid nanomaterial can be used as a substrate for SERS, as reported in Refs. $[42,43]$.

\subsection{Electrochemical and analytical performance}

In reports by Canevari and co-workers [7,9,27], metal nanoparticles confined on electrode surfaces are active catalysts for a variety of electrochemical reactions. Surfaces can be modified simply by coating with an ultrathin film containing these metals. The evaluation of the electrochemical performance of the electrode modified with a PC-AgNP ultrathin film was conducted in $0.1 \mathrm{~mol} \mathrm{~L}^{-1}$ phosphate buffer solution by cyclic voltammetry, to investigate the electrochemical properties of the PC-AgNP on the conductive substrate. A typical cyclic voltammogram is presented in Fig. 4A, which shows two peaks: an anodic at $+400 \mathrm{mV}\left(E_{P A}\right)$ and 
a cathodic at $+178 \mathrm{mV}\left(E_{P C}\right)$. The observed anodic and cathodic peak potentials in Fig. $4 \mathrm{~A}$ can be attributed to the redox of $\mathrm{Ag}^{\mathrm{O} /+}$ in the nanocomposite, in which the electroactive AgNPs are oxidized to $\mathrm{Ag}^{+}$at $0.4 \mathrm{~V}$ vs. $\mathrm{Ag} / \mathrm{AgCl}$ on the forward anodic scan, with conversion of $\mathrm{Ag}^{+}$back to $\mathrm{Ag}^{0}$ at $0.178 \mathrm{~V}$ vs. $\mathrm{Ag} / \mathrm{AgCl}$ on the reversed cathodic scan. This observation further demonstrated that AgNPs were successfully immobilized onto the PC surface, in agreement with the HAADF-TEM micrographs. There was a shift in the oxidation potential toward more positive values compared with other studies containing silver nanostructures supported on other carbonaceous materials, carbon nanotubes or graphene [7,9,46,47]. This shift may be related to the size of the AgNPs and synergistic effects of the silver nanoparticles and PC that constitute the hybrid material.

The voltammetric profile of electrodes modified with PC-Ag was in agreement with the results obtained by others $[7,9,47]$ in studies using modified electrodes containing silver nanostructures. These processes can be attributed to a quasi-reversible system (confirmed by a $\Delta E_{p} \approx 222 \mathrm{mV}$ ) by a single electron transfer between the redox couple $\mathrm{Ag}^{+} / \mathrm{Ag}^{0}$. The surface concentration of electroactive species $\left(\Gamma / \mathrm{mol} \mathrm{cm} \mathrm{cm}^{-2}\right)$ was estimated from the background-corrected electric charge $(Q)$, under the anodic peaks in accordance with the theoretical relationship [48] as follows: $\Gamma=Q / n F A$, where $Q(C)$ is the background-corrected electric charge, calculated by integrating the anodic peak of the cyclic voltammogram $\left(v=5 \mathrm{mV} \mathrm{s}^{-1}\right)$ in PBS solution; $n$ is the number of electrons transferred; $F$ is the Faraday constant $\left(96,485.34 \mathrm{C} \mathrm{mol}^{-1}\right)$; and $A$ is the electrode geometric area. Under the conditions described above, $Q$ was approximately $4.8 \times 10^{-5} \mathrm{C}$, and the estimated surface concentration was $6.97 \times 10^{-9} \mathrm{~mol} \mathrm{~cm}^{-2}$. To determine the influence of oxygen on the electrochemical behavior of the GC/PC-AgNP, some experiments were performed in deaerated solutions, and the profile showed no marked alteration in redox potential or current with the dissolved $\mathrm{O}_{2}$.

The effect of the potential scan rates $\left(5-100 \mathrm{mV} \mathrm{s}^{-1}\right)$ on the voltammetric response for an electrode coated with PC-AgNP ultrathin film in $0.1 \mathrm{~mol} \mathrm{~L}^{-1}$ phosphate buffer solution was investigated, to elucidate the electron-transfer mechanism. The recorded cyclic voltammograms revealed that the anodic peak current increased and the cathodic peak potential shifted as the scan-rate increased. The anodic peak current varied linearly with the scan rates. This linearity indicates that the redox process follows a surface-controlled mechanism [48-50]. A plot of log [peak current] versus $\log$ [scan rate] was performed and is illustrated in Fig. 4B for the glassy carbon electrode coated with PC-AgNP in $0.1 \mathrm{~mol} \mathrm{~L}^{-1}$ phosphate buffer. The slope obtained for the anodic curve was 0.57 ( $R=0.999$ ), which is close to the theoretical value of 0.5 for a surface-controlled mechanism [50]. These features are very convenient diagnostic tools to test for the diffusion-controlled mechanism of a redox process, which is consistent with our results.

The degree of kinetic reversibility exhibited by the redox process on the surface depends on the scan rate of potentials. It is expected that a redox process exhibits a reversible behavior when the potential scan rate is small and an irreversible behavior when the potential scan rate is high [50].

Comparative voltammetric analysis of GA oxidation on a bare glassy carbon electrode (GC), or electrodes coated with Printex L6 carbon (GC/PC) or Printex L6 carbon with silver nanoparticle (PCAgNP) was carried out. Fig. $5 \mathrm{~A}$ presents representative differential pulse voltammograms recorded for GA oxidation on different materials. It can be clearly observed that the oxidation current recorded using the PC-AgNP was higher than that of the PC, among all PC materials. It seems clear that the presence of AgNPs within the carbon lattice can facilitate the electron transfer between GA and the electrode surface, which occurs at a slightly lower potential than on the PC surface. The second important aspect is the sensitivity, which can be evaluated by measuring the peak current intensity using the same amount of material. Fig. 5B demonstrates that the PC and PC-AgNP modified electrodes showed significantly higher peak currents than the bare GC electrode, which can be attributed to the fact that PC has more structural defects and thus a greater electroactive surface area than GC [51]. Moreover, PC-AgNP promoted a synergetic effect between AgNP and carbonaceous materials, thus facilitating charge transference between GA and the electrode surface [29]. Interestingly, this result is consistent with the functionalization degree shown by Raman spectroscopy (i.e. low surface disorder), thus confirming that the formation of the hybrid nanomaterial does not seem to induce extra structural disorder and/or defects within the carbonaceous domains. In this way, the $\mathrm{D} / \mathrm{G}$ ratio was higher for PC-AgNP than PC, consistent with the DPV experiments.

The larger signal obtained with PC-AgNP as compared to PC suggests an active role of AgNPs in the oxidative process. In this case, the silver nanoparticles act like a "front door" for the transfer of electrons between the organic molecule and the electrode surface. Overall, it can be deduced that the metallic nanoparticles dominate the electrochemical behavior of the Printex L6 nanocarbon towards the oxidation of GA. After $50 \mathrm{CV}$ measurements the silver signal $(0.4 \mathrm{~V})$ was maintained, so we can conclude that the AgNPs are stable and they are not leached out in solution.

GA presents pKa values of $4.5(-\mathrm{OH})$ and $10(-\mathrm{COOH})$, the carboxylic group is deprotonated at $\mathrm{pH}=7.0$. In general, the DPV indicated that the electrochemical oxidation of GA was represented by an anodic peak for all of the electrodes tested. The oxidation mechanism of the GA involves the transfer of two electrons and two protons as demonstrated previously [52]. The above-mentioned
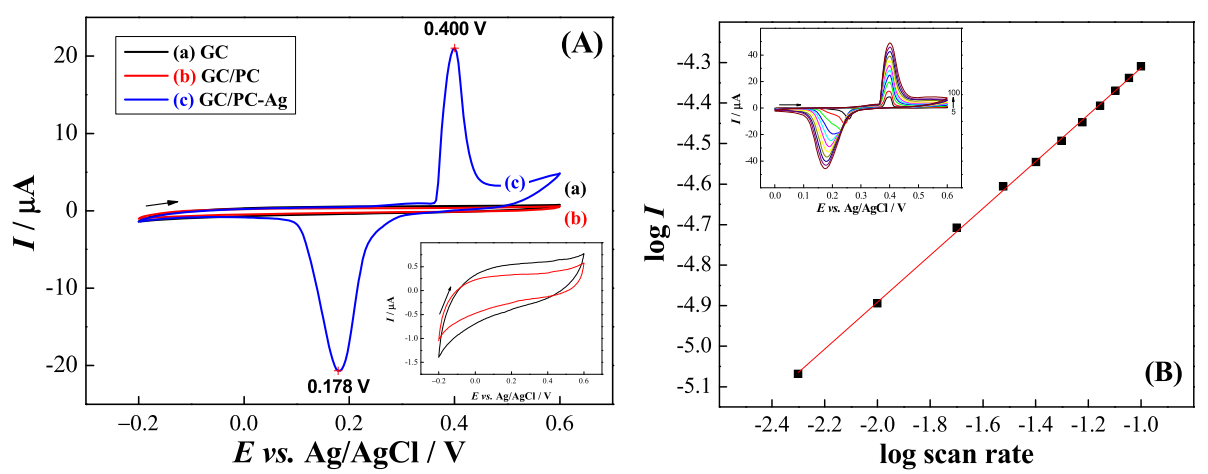

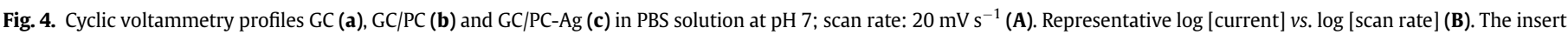
in (B) shows cyclic voltammograms obtained at different scan rates for the modified electrode. 

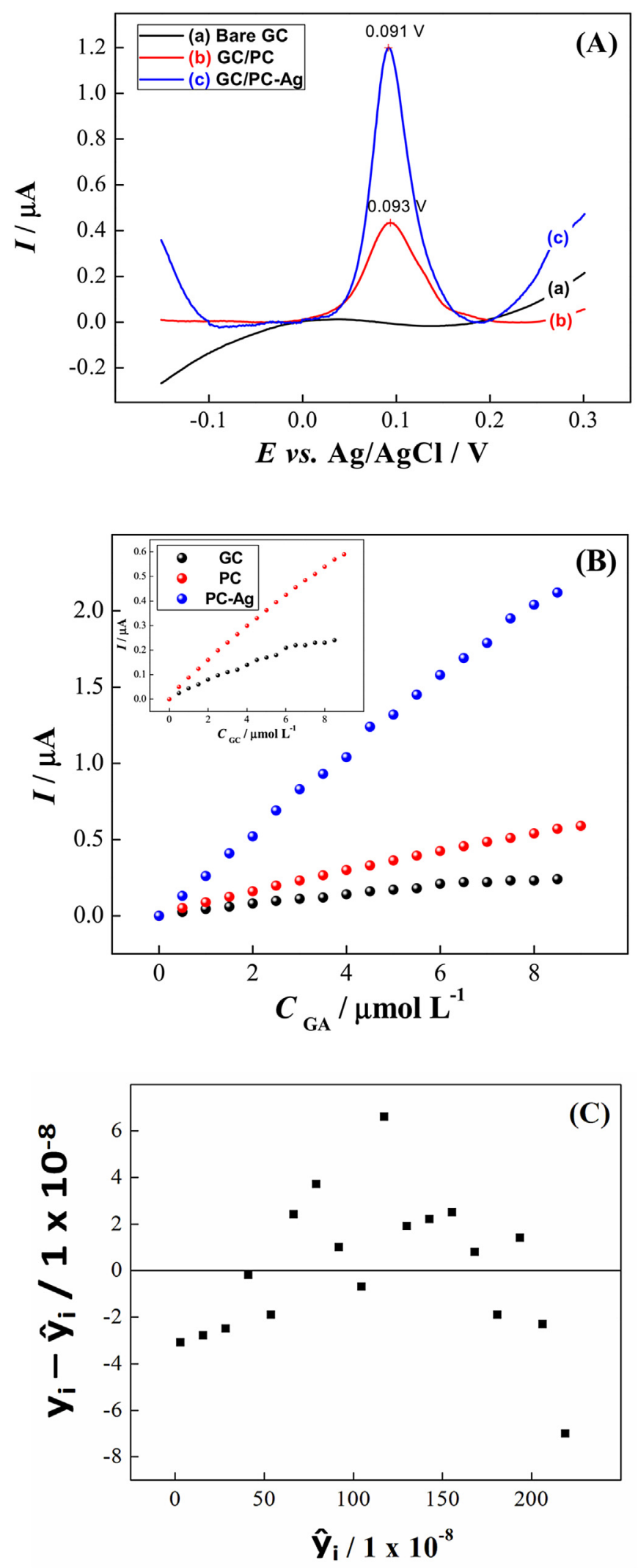

Fig. 5. (A) Differential pulse voltammograms of $8.5 \mu \mathrm{M}$ GA on glassy carbon (a), glassy carbon coated with PC (b) or PC-AgNP (c). (B) Calibration curves of GA on different materials. Conditions: $0.1 \mathrm{M}$ phosphate buffer solution, $\mathrm{pH}$ 7.0. (C) Residual plots of regression diagnosis. oxidation process can be attributed to the well-described route for the oxidation of hydroquinones, phenols and derivatives [1] as shown in Scheme 1.

Therefore, in order to probe the analytical performance of the electrodes toward GA, DPV was applied in the quantitative tests. The DPV electrochemical technique offers more advantages for quantitative analysis than CV due to its merits of background response and lower capacitive current, as well as higher current sensitivity [53]. Fig. S1 demonstrates the dependence of DPVs on the concentrations of $\mathrm{GA}\left(C_{\mathrm{GA}}\right)$ under the optimal conditions. For a detailed assessment on the performance of the nanomaterials, further investigations on the calibration sensitivity, linearity of response and selectivity of the materials were conducted. Fig. 5B illustrates the calibration plots for GA oxidation on bare GC and modified electrodes recorded in the concentration range between $5.0 \times 10^{-7}$ and $8.5 \times 10^{-6} \mathrm{~mol} \mathrm{~L}^{-1}$ (please refer to Fig. S1 for the detailed DPV profiles). Table 1 tabulates the slope, correlation coefficient and anodic peak potential $\left(E_{\mathrm{P}}\right)$ values for each material. In terms of calibration sensitivity, PC-Ag exhibited the most sensitive response to oxidation of GA with the highest slope value of $0.254 \mathrm{~A} \mathrm{~mol}^{-1} \mathrm{~L}$. These results are in agreement with the $\mathrm{D} / \mathrm{G}$ ratio calculated by Raman spectroscopy. Unlike bare GC, PC and PC-AgNP materials showed a good linear relationship between the peak current and the concentration of GA with $\mathrm{R}^{2}$ values close to one. The residual plots in Fig. $5 \mathrm{C}$ demonstrate a satisfactory distribution of residuals (except for $y_{10}$ and $y_{18}$, which might be outliers) demonstrating the correctness of the linear regression. The good results in the electroanalytical performance highlight the synergetic effect of PC-Ag in the electro-oxidation of GA [7,65] indicating that this sensor may represent an excellent alternative for GA detection.

The detection limit was calculated following the method described in the experimental section and the value obtained for the PC-AgNP sensor was $66.3 \times 10^{-9} \mathrm{~mol} \mathrm{~L}^{-1}$. This low detection limit can be explained by the synergetic effect between carbonaceous nanostructure and the silver nanoparticles in the hybrid material, facilitating the electron transfer from GA. The GC/PCAgNP electrode presented convincing repeatability without significant loss of electrocatalytic activity, with a relative standard deviation (RSD) that was less than $5 \%$.

Some molecules that can coexist with GA in wine samples were also investigated. Under the optimized conditions, the oxidation peak of $2.0 \times 10^{-6} \mathrm{~mol} \mathrm{~L}^{-1} \mathrm{GA}$ was examined in the presence of the common interfering species with equal concentrations of glucose, ethanol and sulfite ions. These substances did not significantly influence the detection of GA since the RSD of the peak current changes was $3.7 \%$.

Repeatability of the fabricated sensor was evaluated at the same concentration $\left(2.0 \times 10^{-6} \mathrm{~mol} \mathrm{~L}^{-1}\right)$ of GA in $0.1 \mathrm{~mol} \mathrm{~L}^{-1}$ phosphate buffer solution ( $\mathrm{pH}$ 7.0). The RSD obtained for the peak current of GA changes, for intra-day repeatability $(n=10)$, was $5.3 \%$, suggesting that the prepared sensor had good stability. This could be ascribed to the excellent stability of the surface thin film formed with DMF as a solvent and the chemical stability of the AgNP and PC in the nanocomposite hybrid. When five parallel-fabricated sensors were utilized for the detection of $2.0 \times 10^{-6} \mathrm{~mol} \mathrm{~L}^{-1} \mathrm{GA}$ in a $0.1 \mathrm{~mol} \mathrm{~L}^{-1}$ phosphate buffer solution (pH 7.0), the RSD for inter-day repeatability was $4.7 \%$, indicating a good reproducibility of the sensor fabrication in the detection of GA. Moreover, the stability of the sensor was also evaluated in the presence of a $2.0 \times 10^{-6} \mathrm{~mol} \mathrm{~L}^{-1} \mathrm{GA}$ solution in $0.1 \mathrm{~mol} \mathrm{~L}^{-1}$ phosphate buffer ( $\mathrm{pH}$ 7.0). For this, 50 measurements were recorded and the initial electrochemical response decreased by only $9.8 \%$ (RSD).

Table 2 list the efficiency of the GC/PC-AgNP electrode 

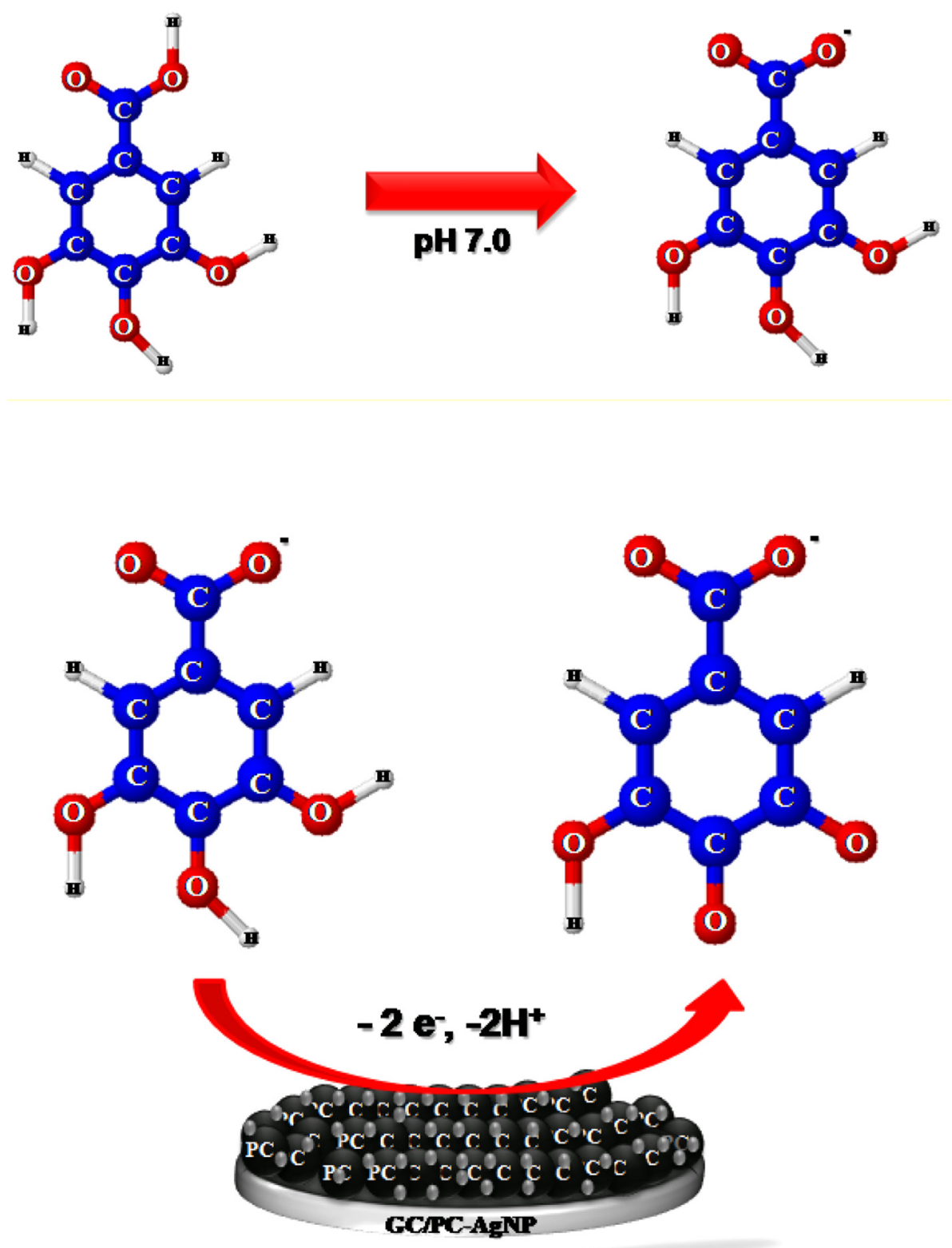

Scheme 1. Schematic representation of the electrocatalytic reaction of GA on the GC/PC-AgNP electrode.

Table 1

Slope, correlation coefficient and peak potential for DPV measurements of GA (concentration range: $5.0 \times 10^{-7}$ to $8.5 \times 10^{-6} \mathrm{~mol} \mathrm{~L}^{-1}$ ) on bare glassy carbon electrode (GC), glassy carbon electrode coated with Printex L6 carbon (GC/PC) or Printex L6 carbon with silver nanoparticles (GC/PC-AgNP).

\begin{tabular}{llll}
\hline Material & $\begin{array}{l}\text { Slope } \\
\left(\mathrm{A} \mathrm{M}^{-1}\right)\end{array}$ & $\mathrm{R}^{2}$ & $\begin{array}{l}E_{\mathrm{P}} \\
(\mathrm{mV} \text { vs. } \mathrm{Ag} / \mathrm{AgCl})\end{array}$ \\
\hline Bare GC & - & - & - \\
GC/PC & 0.065 & 0.995 & 93 \\
GC/PC-Ag & 0.254 & 0.998 & 91 \\
\hline
\end{tabular}

compared with others electroanalytical approaches used for sensing gallic acid performances with transducers different. The limit of detection this sensor can be considerably competitive with similar devices for GA detection in comparison with most modified materials.

\subsection{Determination and statistical comparison of antioxidant capacity of wines using GA as the standard}

In order to validate the proposed voltammetric methods, the results obtained in the analysis of total phenolic compounds of low oxidation potential values in different real wine samples were compared with those determined by using the spectrophotometric method. Fig. 6 demonstrates a good correlation between sensor proposed and standard method, and an intercept value very close to zero. The slope and product-moment correlation coefficient are also close to one indicating that the two techniques are equivalent, since the deviation from the ideal case can be associated with the random errors present. The Student's t-test was carried out to support the obtained result $[34,61]$ in which was about 25.0 demonstrating no significant difference between the two techniques. This value was bigger than the t-critical value $(4.30-95 \%$ of significance for $\mathrm{n}=4$ (degrees of freedom $=2 ; \alpha=0.05)$ ). Thus, we 
Table 2

Selected electroanalytical approaches used for sensing gallic acid performances with ten transducers different.

\begin{tabular}{|c|c|c|c|c|c|}
\hline Sensing layer & Transduction & $\begin{array}{l}\text { Sensitivity } \\
\left(\mu \mathrm{A} / \mathrm{mol} \mathrm{L}^{-1}\right)\end{array}$ & $\begin{array}{l}\text { LOD } \\
(\mu \mathrm{M})\end{array}$ & $\begin{array}{l}\text { Linear range } \\
\left(\mathrm{mol} \mathrm{L}^{-1}\right)\end{array}$ & Reference \\
\hline CPME/CNT & DPV & $8.27 \times 10^{2}$ & 0.3 & $5.0 \times 10^{-7}-1.5 \times 10^{-5}$ & [1] \\
\hline $\mathrm{GC} / \mathrm{CS}-\mathrm{fFe}_{2} \mathrm{O}_{3}-\mathrm{ERGO}$ & DPV & - & 0.15 & $1.0 \times 10^{-6}-5.0 \times 10^{-5}$ & [53] \\
\hline $\mathrm{CPE} / \mathrm{SiO}_{2}$-nano & DPV & 1790.70 & 0.25 & $8.0 \times 10^{-7}-1.0 \times 10^{-4}$ & [54] \\
\hline CB-SPE & $\mathrm{CV}$ & 2.91 & 1.0 & $10-100 \times 10^{-6}$ & [55] \\
\hline \multirow[t]{2}{*}{ CPME/Ruthenium oxo-complex } & LSV & 0.727 & 1.43 & $2.64-11.7 \times 10^{-6}$ & \multirow[t]{2}{*}{ [56] } \\
\hline & $\mathrm{CA}$ & 2.89 & 0.49 & $6.61-191 \times 10^{-6}$ & \\
\hline \multirow[t]{2}{*}{ SPE/PME } & \multirow[t]{2}{*}{ FIA } & 0.111 & 0.076 & $0.5-2500 \times 10^{-6}$ & \multirow[t]{2}{*}{ [57] } \\
\hline & & 0.012 & 0.21 & $1-1000 \times 10^{-6}$ & \\
\hline GCE/o-DD@MWCNT & $\mathrm{CA}$ & - & 0.144 & $100-1300 \times 10^{-6}$ & [58] \\
\hline GC/SWCNTs-Polytyr & $\mathrm{CA}$ & 0.16 & 0.0088 & $5.0 \times 10^{-7}-1.7 \times 10^{-4}$ & [59] \\
\hline $\mathrm{TH} / \mathrm{NiHCF}$ & $\mathrm{CV}$ & - & 1.66 & $4.99 \times 10^{-6}-1.2 \times 10^{-3}$ & {$[60]$} \\
\hline GC/PC-Ag & DPV & 0.254 & 0.0663 & $5.0 \times 10^{-7}-8.5 \times 10^{-6}$ & This work \\
\hline
\end{tabular}

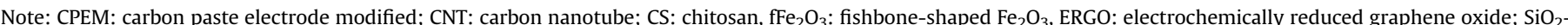

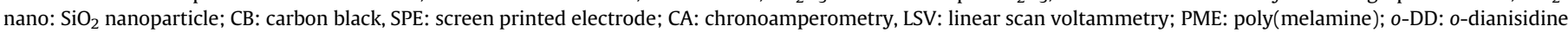
derivative, MWCNT: multi-walled carbon nanotube; Polytyr: polytyrosine, SWCNT: single-walled carbon nanotube; TH: thionine, NiHCF: nickel hexacyanoferrate.

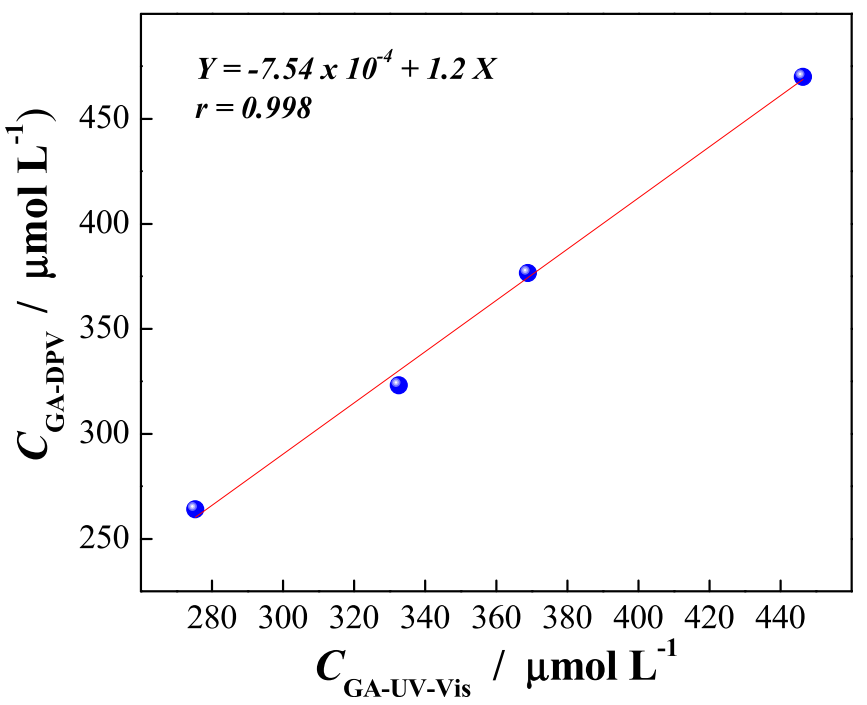

Fig. 6. Correlation between the results obtained by the proposed electroanalytical method and the standard (spectrophotometric) method.

can conclude that the proposed method is analogous to the standard method (UV-Vis spectrophotometric) in estimating the total polyphenols in wine samples. As shown in Fig. 5, the phenolic content determined by electroanalytical methods was lower than that obtained by the spectrophotometric method, likely because the standard method is less selective [62]. Nevertheless, we found that the proposed electroanalytical method using PC-Ag electrodes is capable of estimating the antioxidant power, because it is more selective, faster and more sensitive, and does not require any sample pretreatment [62-64].

The low cost of PC nanomaterials and the possibility of developing miniaturized devices, coupled with the satisfactory analytical sensor performances, make this sensor a suitable tool for electrochemical applications. The relevant electrochemical properties of PC confirm the high potential of this cost-effective nanomaterial to compete with the commonly used graphene, carbon nanotubes and carbon black for use in electrochemical sensors.

\section{Conclusion}

Here we propose a electrochemical sensor based on PC-AgNP for the determination of GA and estimation of antioxidant activity in wine. The PC-Ag nanocomposite was successfully characterized by TEM, EDX, SAED, XRD, Raman and voltammetric techniques, which indicated that the PC-AgNP nanostructured material was supported on the GC surface with primary particles with a radius of approximately 20-25 nm ('nano-carbon') and $2 \mathrm{~nm}$ (AgNP) was found to nanostructure the electrode surface, leading to oxidation of GA at lower potentials, yielding higher current responses. Therefore, the electrochemical properties and catalytic ability of PC showed good efficiency in the estimation of total polyphenols in wine. An advantage of the composite preparation development is that it is not time consuming. Finally, the electroanalytical properties and high catalytic activity of the PC-Ag yielded values for the detection limit in the nanomolar range, improved reproducibility and repeatability and produced excellent sensitivity. In essence, this study highlights the potential improvement involved in the (largely unexplored) direct application of nanocarbon in electrode surface modification.

\section{Acknowledgments}

The authors are thankful to São Paulo Research Foundation FAPESP (2012/17689-9 and 2014/05197-0), CNPq and CAPES for the financial support. The scholarships granted by the São Paulo Research Foundation, FAPESP (2012/17689-9 and 2014/05197-0) to Paulo Augusto Raymundo-Pereira and Anderson Massahiro de Campos, respectively, are gratefully acknowledged.

Degussa Corporation and Prof. Dr. Marcos R. V. Lanza are acknowledged for the generous donation of the Printex L6 carbon used in this work. Carlos J. L. Constantino is specifically acknowledged for the Raman measurements.

\section{Appendix A. Supplementary data}

Supplementary data related to this article can be found at http:// dx.doi.org/10.1016/j.aca.2016.04.036.

\section{References}

[1] L.P. Souza, F. Calegari, A.J.G. Zarbin, L.H. Marcolino, M.F. Bergamini, Voltammetric determination of the antioxidant capacity in wine samples using a carbon nanotube modified electrode, J. Agr. Food Chem. 59 (2011) $7620-7625$.

[2] F.A. Daria Talarico, A. Constantino, M. Del Carlo, D. Compagnone, D. Moscone, G. Palleschi, Carbon black as successful screen-printed electrode modifier for phenolic compound detection, Electrochem Commun. 60 (2015) 78-82.

[3] P.A. Kilmartin, H.L. Zou, A.L. Waterhouse, A cyclic voltammetry method suitable for characterizing antioxidant properties of wine and wine phenolics, J. Agr. Food Chem. 49 (2001) 1957-1965. 
[4] R. Stevanato, S. Fabris, F. Momo, New enzymatic method for the determination of total phenolic content in tea and wine, J. Agric. Food Chem. 52 (2004) $6287-6293$.

[5] F. Arduini, A. Amine, C. Majorani, F. Di Giorgio, D. De Felicis, F. Cataldo, D. Moscone, G. Palleschi, High performance electrochemical sensor based on modified screen-printed electrodes with cost-effective dispersion of nanostructured carbon black, Electrochem Commun. 12 (2010) 346-350.

[6] T.C. Canevari, P.A. Raymundo-Pereira, R. Landers, E.V. Benvenutti S.A.S. Machado, Sol-gel thin-film based mesoporous silica and carbon nanotubes for the determination of dopamine, uric acid and paracetamol in urine, Talanta 116 (2013) 726-735.

[7] T.C. Canevari, P.A. Raymundo-Pereira, R. Landers, S.A.S. Machado, Direct synthesis of Ag nanoparticles incorporated on a mesoporous hybrid material as a sensitive sensor for the simultaneous determination of dihydroxybenzenes isomers, Eur. J. Inorg. Chem. 2013 (2013) 5746-5754.

[8] F. Arduini, F. Di Nardo, A. Amine, L. Micheli, G. Palleschi, D. Moscone, Carbon black-modified screen-printed electrodes as electroanalytical tools, Electroanal 24 (2012) 743-751.

[9] F.H. Cincotto, T.C. Canevari, A.M. Campos, R. Landers, S.A.S. Machado, Simultaneous determination of epinephrine and dopamine by electrochemical reduction on the hybrid material $\mathrm{SiO}_{2}$ /graphene oxide decorated with $\mathrm{Ag}$ nanoparticles, Analyst 139 (2014) 4634-4640.

[10] R.C. Carvalho, A. Mandil, K.P. Prathish, A. Amine, C.M.A. Brett, Carbon nanotube, carbon black and copper nanoparticle modified screen printed electrodes for amino acid determination, Electroanal 25 (2013) 903-913.

[11] M. Portaccio, D. Di Tuoro, F. Arduini, D. Moscone, M. Cammarota, D.G. Mita, M. Lepore, Laccase biosensor based on screen-printed electrode modified with thionine-carbon black nanocomposite, for Bisphenol A detection, Electrochim. Acta 109 (2013) 340-347.

[12] T.W.B. Lo, L. Aldous, R.G. Compton, The use of nano-carbon as an alternative to multi-walled carbon nanotubes in modified electrodes for adsorptive stripping voltammetry, Sens. Actuat. B Chem. 162 (2012) 361-368.

[13] S. Cinti, F. Arduini, M. Carbone, L. Sansone, I. Cacciotti, D. Moscone G. Palleschi, Screen-printed electrodes modified with carbon nanomaterials: comparison among carbon black, carbon nanotubes and graphene, Electroanal 27 (2015) 2230-2238.

[14] S. Cinti, F. Arduini, G. Vellucci, I. Cacciotti, F. Nanni, D. Moscone, Carbon black assisted tailoring of Prussian Blue nanoparticles to tune sensitivity and detection limit towards $\mathrm{H}_{2} \mathrm{O}_{2}$ by using screen-printed electrode, Electrochem Commun. 47 (2014) 63-66.

[15] M.H.M.T. Assumpcao, R.F.B. De Souza, D.C. Rascio, J.C.M. Silva, M.L. Calegaro, I. Gaubeur, T.R.L.C. Paixao, P. Hammer, M.R.V. Lanza, M.C. Santos, A comparative study of the electrogeneration of hydrogen peroxide using Vulcan and Printex carbon supports, Carbon 49 (2011) 2842-2851.

[16] W.Y. Han, W.P. Zhu, P.Y. Zhang, Y. Zhang, L.S. Li, Photocatalytic degradation of phenols in aqueous solution under irradiation of 254 and $185 \mathrm{~nm}$ UV light, Catal. Today 90 (2004) 319-324.

[17] P.Y. Zhang, J. Liu, Photocatalytic degradation of trace hexane in the gas phase with and without ozone addition: kinetic study, J. Photochem. Photobiol. A 167 (2004) 87-94.

[18] L.S. Li, P.Y. Zhang, W.P. Zhu, W.Y. Han, Z.L. Zhang, Comparison of O-3-BAC, UV/ $\mathrm{O}-3-\mathrm{BAC}$ and $\mathrm{TiO} / \mathrm{UV} / \mathrm{O}-3-\mathrm{BAC}$ processes for removing organic pollutants in secondary effluents, J. Photochem. Photobiol. A 171 (2005) 145-151.

[19] L.S. Li, W.P. Zhu, P.Y. Zhang, Z.Y. Chen, W.Y. Han, Photocatalytic oxidation and ozonation of catechol over carbon-black-modified nano- $\mathrm{TiO}_{2}$ thin films supported on A1 sheet, Water Res. 37 (2003) 3646-3651.

[20] W.R.P. Barros, T. Ereno, A.C. Tavares, M.R.V. Lanza, In Situ electrochemical generation of hydrogen peroxide in alkaline aqueous solution by using an unmodified gas diffusion electrode, Chemelectrochem 2 (2015) 714-719.

[21] W.R.P. Barros, P.C. Franco, J.R. Steter, R.S. Rocha, M.R.V. Lanza, Electro-Fenton degradation of the food dye amaranth using a gas diffusion electrode modified with cobalt (II) phthalocyanine, J. Electroanal. Chem. 722 (2014) 46-53.

[22] W.R.P. Barros, R.M. Reis, R.S. Rocha, M.R.V. Lanza, Electrogeneration of hydrogen peroxide in acidic medium using gas diffusion electrodes modified with cobalt (II) phthalocyanine, Electrochim. Acta 104 (2013) 12-18.

[23] W.R.P. Barros, Q.L. Wei, G.X. Zhang, S.H. Sun, M.R.V. Lanza, A.C. Tavares, Oxygen reduction to hydrogen peroxide on $\mathrm{Fe} 3 \mathrm{O} 4$ nanoparticles supported on Printex carbon and Graphene, Electrochim. Acta 162 (2015) 263-270.

[24] R.M. Reis, R.S. Rocha, M.R.V. Lanza, Electrogeneration of $\mathrm{H}_{2} \mathrm{O}_{2}$ in acid medium using catalysts modified with manganese II phthalocyanine supported in Printex 6L carbon, ECS Trans. 43 (2012) 103-109.

[25] S. Cinti, S. Politi, D. Moscone, G. Palleschi, F. Arduini, Stripping analysis of $\mathrm{As}(\mathrm{III})$ by means of screen-printed electrodes modified with gold nanoparticles and carbon black nanocomposite, Electroanal 26 (2014) 931-939.

[26] F. Arduini, C. Zanardi, S. Cinti, F. Terzi, D. Moscone, G. Palleschi, R. Seeber Effective electrochemical sensor based on screen-printed electrodes modified with a carbon black-Au nanoparticles composite, Sens. Actuat. B Chem. 212 (2015) 536-543.

[27] T.C. Canevari, F.H. Cincotto, R. Landers, S.A.S. Machado, Synthesis and characterization of alpha-nickel (II) hydroxide particles on organic-inorganic matrix and its application in a sensitive electrochemical sensor for vitamin D determination, Electrochim. Acta 147 (2014) 688-695.

[28] C. Zanardi, L. Pigani, R. Seeber, F. Terzi, F. Arduini, S. Cinti, D. Moscone, G. Palleschi, Carbon black/gold nanoparticles composite for efficient amperometric sensors, Lect. Notes Electr. Engg. 319 (2015) 159-163.
[29] I. Cesarino, F.H. Cincotto, S.A.S. Machado, A synergistic combination of reduced graphene oxide and antimony nanoparticles for estriol hormone detection, Sens. Actuat. B Chem. 210 (2015) 453-459.

[30] D. Agustini, A.S. Mangrich, M.F. Bergamini, L.H. Marcolino, Sensitive voltammetric determination of lead released from ceramic dishes by using of bismuth nanostructures anchored on biochar, Talanta 142 (2015) 221-227.

[31] F.R. Caetano, A. Gevaerd, E.G. Castro, M.F. Bergamini, A.J.G. Zarbin, L.H. Marcolino, Electroanalytical application of a screen-printed electrode modified by dodecanethiol-stabilized platinum nanoparticles for dapsone determination, Electrochim. Acta 66 (2012) 265-270.

[32] E.G.C. Neiva, M.F. Bergamini, M.M. Oliveira, L.H. Marcolino, A.J.G. Zarbin, PVPcapped nickel nanoparticles: synthesis, characterization and utilization as a glycerol electrosensor, Sens. Actuat. B Chem. 196 (2014) 574-581.

[33] S.E. Skrabalak, B.J. Wiley, M. Kim, E.V. Formo, Y.N. Xia, On the polyol synthesis of silver nanostructures: glycolaldehyde as a reducing agent, Nano Lett. 8 (2008) 2077-2081.

[34] F.C. Vicentini, P.A. Raymundo-Pereira, B.C. Janegitz, S.A.S. Machado, O. Fatibello-Filho, Nanostructured carbon black for simultaneous sensing in biological fluids, Sensor Actuat. B-Chem. 227 (2016) 610-618, http:/l dx.doi.org/10.1016/j.snb.2015.12.094.

[35] J.N. Miller, Basic statistical-methods for analytical-chemistry .2. Calibration and regression methods - a review, Analyst 116 (1991) 3-14.

[36] Y.N. Ni, P. Qiu, S. Kokot, Simultaneous determination of three organophosphorus pesticides by differential pulse stripping voltammetry and chemometrics, Anal. Chim. Acta 516 (2004) 7-17.

[37] Y.N. Ni, P. Qiu, S. Kokot, Simultaneous voltammetric determination of four carbamate pesticides with the use of chemometrics, Anal. Chim. Acta 537 (2005) 321-330.

[38] Y.N. Ni, L. Wang, S. Kokot, Voltammetric determination of butylated hydroxyanisole, butylated hydroxytoluene, propyl gallate and tertbutylhydroquinone by use of chemometric approaches, Anal. Chim. Acta 412 (2000) 185-193.

[39] J.W. Schoonen, M.G.F. Sales, Determination of polyphenols in wines by reaction with 4-aminoantipyrine and photometric flow-injection analysis, Anal. Bioanal. Chem. 372 (2002) 822-828.

[40] P. Stratil, B. Klejdus, V. Kuban, Determination of phenolic compounds and their antioxidant activity in fruits and cereals, Talanta 71 (2007) 1741-1751.

[41] S. Nath, S.K. Ghosh, S. Praharaj, S. Panigrahi, S. Basu, T. Pal, Silver organosol: synthesis, characterisation and localised surface plasmon resonance study, New J. Chem. 29 (2005) 1527-1534.

[42] J.E.S. Fonsaca, A.L. Elias, S.H. Domingues, M.M. Oliveira, M. Endo, E.S. Orth, M. Terrones, A.J.G. Zarbin, Graphene nanoribbons inducing cube-shaped Ag nanoparticle assemblies, Carbon 93 (2015) 800-811.

[43] H. Mehl, M.M. Oliveira, A.J.G. Zarbin, Thin and transparent films of graphene/ silver nanoparticles obtained at liquid-liquid interfaces: Preparation, characterization and application as SERS substrates, J. Colloid Interface Sci. 438 (2015) 29-38

[44] A.C. Ferrari, J.C. Meyer, V. Scardaci, C. Casiraghi, M. Lazzeri, F. Mauri, S. Piscanec, D. Jiang, K.S. Novoselov, S. Roth, A.K. Geim, Raman spectrum of graphene and graphene layers, Phys. Rev. Lett. 97 (2006).

[45] A.C. Ferrari, J. Robertson, Interpretation of Raman spectra of disordered and amorphous carbon, Phys. Rev. B 61 (2000) 14095-14107.

[46] K. Cui, Y.H. Song, Y. Yao, Z.Z. Huang, L. Wang, A novel hydrogen peroxide sensor based on Ag nanoparticles electrodeposited on DNA-networks modified glassy carbon electrode, Electrochem. Commun. 10 (2008) 663-667.

[47] J.H. Li, D.Z. Kuang, Y.L. Feng, F.X. Zhang, Z.F. Xu, M.Q. Liu, D.P. Wang, Green synthesis of silver nanoparticles-graphene oxide nanocomposite and its application in electrochemical sensing of tryptophan, Biosens. Bioelectron. 42 (2013) 198-206.

[48] P.A. Raymundo-Pereira, C.S. Martin, M.F. Bergamini, N. Bocchi, M.F.S. Teixeira, Electrochemical evaluation of the a carbon-paste electrode modified with spinel manganese(IV) oxide under flow conditions for amperometric determination of lithium, Electrochim. Acta 56 (2011) 2552-2558.

[49] P.A. Raymundo-Pereira, M.F.S. Teixeira, O. Fatibello, E.R. Dockal, V.G. Bonifacio, L.H.M. Lino, Electrochemical sensor for ranitidine determination based on carbon paste electrode modified with oxovanadium (IV) salen complex, Mat. Sci. Eng. C Mater. 33 (2013) 4081-4085.

[50] E. Laviron, General expression of the linear potential sweep voltammogram in the case of diffusionless electrochemical systems, J. Electroanal. Chem. 101 (1979) 19-28.

[51] A. Ambrosi, A. Bonanni, Z. Sofer, J.S. Cross, M. Pumera, Electrochemistry at chemically modified graphenes, Chem-Eur J. 17 (2011) 10763-10770.

[52] S. Gunckel, P. Santander, G. Cordano, J. Ferreira, S. Munoz, L.J. Nunez-Vergara, J.A. Squella, Antioxidant activity of gallates: an electrochemical study in aqueous media, Chem-Biol. Interact. 114 (1998) 45-59.

[53] F. Gao, D.L. Zheng, H. Tanaka, F.P. Zhan, X.N. Yuan, F. Gao, Q.X. Wang, An electrochemical sensor for gallic acid based on $\mathrm{Fe}_{2} \mathrm{O}_{3} /$ electro-reduced graphene oxide composite: Estimation for the antioxidant capacity index of wines, Mat. Sci. Eng. C Mater. 57 (2015) 279-287.

[54] J. Tashkhourian, S.F. Nami-Ana, A sensitive electrochemical sensor for determination of gallic acid based on $\mathrm{SiO}_{2}$ nanoparticle modified carbon paste electrode, Mat. Sci. Eng. C Mater. 52 (2015) 103-110.

[55] D. Talarico, F. Arduini, A. Constantino, M. Del Carlo, D. Compagnone, D. Moscone, G. Palleschi, Carbon black as successful screen-printed electrode modifier for phenolic compound detection, Electrochem. Commun. 60 (2015) 
$78-82$.

[56] P.A. Raymundo-Pereira, M.F.S, Teixeira, F.R. Caetano, M.F. Bergamini, L.H. Marcolino, A simple and rapid estimation of totals polyphenols based on carbon paste electrode modified with ruthenium oxo-complex, Electroanal 27 (2015) 2371-2376.

[57] Y.L. Su, S.H. Cheng, Sensitive and selective determination of gallic acid in green tea samples based on an electrochemical platform of poly(melamine) film, Anal. Chim. Acta 901 (2015) 41-50.

[58] S. Sundaram, M. Jagannathan, M.R.A. Kadir, S. Palanivel, T. Hadibarata A.R.M. Yusoff, A new electro-generated o-dianisidine derivative stabilized MWCNT-modified GCE for low potential gallic acid detection, RSC Adv. 5 (2015) 45996-46006.

[59] M. Eguilaz, A. Gutierrez, F. Gutierrez, J.M. Gonzalez-Dominguez, A. AnsonCasaos, J. Hernandez-Ferrer, N.F. Ferreyra, M.T. Martinez, G. Rivas, Covalent functionalization of single-walled carbon nanotubes with polytyrosine: characterization and analytical applications for the sensitive quantification of polyphenols, Anal. Chim. Acta 909 (2016) 51-59.

[60] N.S. Sangeetha, S.S. Narayanan, A novel bimediator amperometric sensor for electrocatalytic oxidation of gallic acid and reduction of hydrogen peroxide Anal. Chim. Acta 828 (2014) 34-45.
[61] J.N.M. Miller, J.C. Miller, Statistics and Chemometrics for Analytical Chemistry, fifth ed., Pearson Education Limited, Harlow-Essex, UK, 2005.

[62] A. Guiberteau-Cabanillas, B. Godoy-Cancho, E. Bernalte, M. Tena-Villares, C.G. Cabanillas, M.A. Martinez-Canas, Electroanalytical behavior of gallic and ellagic acid using graphene modified screen-printed electrodes. method for the determination of total low oxidation potential phenolic compounds content in cork boiling waters, Electroanal 27 (2015) 177-184.

[63] B.C. Janegitz, M. Baccarin, P.A. Raymundo-Pereira, F.A. Santos, G.G. Oliveira, S.A.S. Machado, M.R.V. Lanza, O. Fatibello-Filho, Zucolotto Valtencir, The use of dihexadecylphosphate in sensing and biosensing, Sensor Actuat. B-Chem. 220 (2015) 805-813, http://dx.doi.org/10.1016/j.snb.2015.06.020.

[64] P.A. Raymundo-Pereira, A.R.F. Lima, S.A.S. Machado, A nanostructured labelfree platform based on an ultrathin film for ultrasensitive detection of a secosteroid hormone, RSC Adv. 6 (2016) 34458-34467, http://dx.doi.org/ 10.1039/C6RA04740H.

[65] A.M. Campos, P.A. Raymundo-Pereira, F.H. Cincotto, T.C. Canevari S.A.S. Machado, Sensitive determination of the endocrine disruptor bisphenol $\mathrm{A}$ at ultrathin film based on nanostructured hybrid material $\mathrm{SiO}_{2} / \mathrm{GO} / \mathrm{AgNP}, \mathrm{J}$. Solid State Electrochem. (2016) 1-5, http://dx.doi.org/10.1007/s10008-0153098-y. 